\title{
Conhecer a Diversidade do Vírus da Hepatite C para Além da Frequência dos Genótipos em Amostras Analisadas entre 2009 e 2014 no Laboratório de Referência do Instituto Nacional de Saúde Dr. Ricardo Jorge
}

\author{
Assessment of Hepatitis C Virus Diversity in Addition to the Frequency of \\ Genotypes in Samples Analyzed Between 2009 and 2014 at the Reference \\ Laboratory of National Health Institute Dr. Ricardo Jorge
}

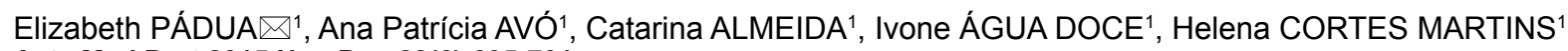
Acta Med Port 2015 Nov-Dec;28(6):695-701

RESUMO

Introdução: A identificação dos genótipos do vírus da hepatite $C$ foi essencial para o prognóstico e tratamento dos doentes crónicos durante os últimos anos. Foram objetivos deste estudo conhecer a frequência de genótipos do vírus da hepatite $\mathrm{C}$ nos últimos seis anos, e revelar o contributo de um ensaio in-house para caracterização molecular do vírus.

Material e Métodos: A genotipagem do vírus da hepatite $C$ por LiPA foi realizada em 923 amostras, maioritariamente provenientes de indivíduos do sexo masculino. A subtipagem do vírus da hepatite $\mathrm{C}$ pelo ensaio in-house com alvo nas regiões Core/E1 e/ou NS5B foi efetuada em 112 amostras.

Resultados: Observámos elevada prevalência do genótipo 1 (56,6\%), sendo a frequência do subtipo 1a quatro vezes superior ao subtipo 1 b. Todos os casos de genótipo $3(27,5 \%)$ foram classificados em subtipo 3a. Nas infeções pelo genótipo 4 (12,9\%), identificaram-se os subtipos $4 \mathrm{a}(65,5 \%), 4 \mathrm{~d}(31 \%), 4 \mathrm{~b}(1,7 \%)$ e 4c $(1,7 \%)$. Foram identificadas a RF1_2k/1b, recombinantes intragenótipo 2 e potenciais infeções mistas na população analisada.

Discussão: Os subtipos mais prevalentes, 1 a e $3 a$, estão descritos como comuns em utilizadores de drogas injetáveis. Apesar da maioria das amostras analisadas corresponder a reclusos $(78,4 \%)$, não podemos excluir eventuais comportamentos de risco associados ao consumo de drogas ilícitas.

Conclusões: A prevalência elevada do subtipo 1a, a frequência e diversidade do genótipo 4 e a identificação de vírus geneticamente recombinados, sugerem alteração do padrão molecular vírus da hepatite $\mathrm{C}$ descrito no passado. $\mathrm{O}$ ensaio in-house implementado revelou ser útil para a correta classificação do vírus da hepatite $\mathrm{C}$ e melhoria do conhecimento sobre a diversidade do vírus em circulação no país.

Palavra-chave: Diversidade Genética; Genótipos; Subtipos; Vírus da Hepatite C.

\section{ABSTRACT}

Introduction: The identification of genotypes was essential for the prognosis and treatment of hepatitis $\mathrm{C}$ virus chronic patients in recent years. The aims of the study were to know the frequency of genotypes diagnosed in the last six years at the laboratory, and reveal the contribution of an in-house assay for molecular characterization of viruses.

Material and Methods: The genotyping of hepatitis C virus by LiPA was performed in 923 samples, mostly from male individuals. The subtyping of hepatitis $C$ virus by an in-house assay to target regions in the Core/E1 and/or NS5B was performed in 112 samples.

Results: We observed a high prevalence of genotype $1(56.6 \%)$, with a frequency of subtype $1 \mathrm{a}$ four times higher compared to $1 \mathrm{~b}$. All cases of genotype $3(27.5 \%)$ were subtype 3a. For the cases of genotype $4(12.9 \%)$, it were identified subtypes $4 a(65.5 \%), 4 d(31 \%)$, $4 \mathrm{~b}(1.7 \%)$ and $4 \mathrm{c}(1.7 \%)$. Recombinants intragenotype 2, the RF1_2k/1b, and mixed infections, were also identified.

Discussion: The most prevalent subtypes (1a and 3a) obtained are usually described in injecting drug users. Although most of the samples analysed match to inmates $(78.4 \%)$, we cannot exclude any possible risk behaviors associated with illicit drug use.

Conclusions: The high prevalence of subtype $1 \mathrm{a}$, the frequency and diversity of genotype 4 , and the identification of recombined virus suggest modification of the molecular pattern of hepatitis $C$ virus infection described in the past. The in-house assay proved to be useful for the correct classification of hepatitis $\mathrm{C}$ virus and improving knowledge about the diversity of virus circulating in the country.

Keywords: Genetic Diversity; Genotypes; Hepatitis C Virus; Subtypes.

\section{INTRODUÇÃO}

A hepatite $C$ é reconhecida como uma doença de importância global em Saúde Pública afetando tanto países desenvolvidos como países em vias de desenvolvimento. $\mathrm{O}$ seu agente etiológico - o vírus da hepatite $\mathrm{C}(\mathrm{VHC})$ é endémico em todo o mundo e a taxa de prevalência da infeção pode variar significativamente, sendo influenciada, quer pelas principais vias de transmissão do vírus, quer pelas políticas de saúde implementadas nos diferentes países para prevenção e tratamento da infeção. ${ }^{1,2} \mathrm{~A}$ Organização Mundial de Saúde estima que entre 150 a 170 milhões de indivíduos estejam infetados pelo $\mathrm{VHC}^{3}$ Embora a incidência da infeção tenha diminuído nos últimos anos, a sua

1. Laboratório Nacional de Referência de Infeções Sexualmente Transmissíveis - VIH e vírus da hepatite B e C. Departamento de Doenças Infeciosas. Instituto Nacional de Saúde Dr. Ricardo Jorge. Lisboa. Portugal.

$\square$ Autor correspondente: Elizabeth Pádua. elizabeth.padua@insa.min-saude.pt

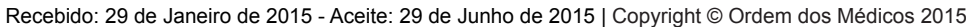


prevalência permanece elevada devido ao desenvolvimento de hepatite $\mathrm{C}$ crónica em cerca de $80 \%$ dos indivíduos infetados. ${ }^{2,4}$

Em Portugal, poucos estudos existem sobre a infeção pelo VHC estimando-se uma prevalência de $1 \%$ a $1,5 \%$ na população portuguesa, estando este vírus associado a $45 \%$ dos casos notificados de hepatite no país. , $^{6}$ É reconhecido, no entanto, que nem todos os casos são notificados e muitos não são diagnosticados. Entre os países europeus, Portugal descreve as taxas de prevalência desta infeção mais elevadas em grupos populacionais Utilizadores de Drogas Injetáveis (UDI), podendo estas variar entre 60 a $80 \% .^{6-8}$

$\mathrm{O}$ VHC é caracterizado por uma grande diversidade genética, traduzida por um elevado número de vírus em circulação, classificados em sete diferentes genótipos e cerca de 67 subtipos virais. ${ }^{9} \mathrm{O}$ vírus apresenta distintos padrões de distribuição epidemiológica no mundo. A taxa de evolução do VHC é rápida e o grau de variabilidade aumenta significativamente ao longo do tempo, resultando no desenvolvimento de quasispecies que são importantes na história natural da infeção e permitem a evasão do vírus ao sistema imunitário do hospedeiro. ${ }^{10}$

Durante os últimos anos e integrada no período do estudo, a terapia combinada de interferão alfa peguilado com ribavirina foi a utilizada como sendo o tratamento padrão para os doentes crónicos. ${ }^{11}$ A eficácia da terapia combinada, determinada pela Resposta Virológica Sustentada (RVS), ou seja, RNA do VHC indetetável 24 semanas após a conclusão do tratamento, ${ }^{12}$ varia entre 42 a $82 \%$ e é dependente do genótipo do vírus em causa. Nas infeções pelo genótipo 1 são observadas as taxas de RVS mais baixas ( $40 \%$ - 50\%) e, em contraste, nas infeções pelos genótipos 2 e 3 são alcançadas as taxas de RVS mais elevadas (80\%). Taxas de RVS de valores intermédios (43\% - 70\%) foram associadas a infeções pelo genótipo 4. ${ }^{11-13}$ Deste modo, os vários genótipos de VHC conduzem a diferente resposta dos doentes ao tratamento padrão. Assim, a identificação dos genótipos tornou-se na ferramenta essencial para a determinação do prognóstico da infeção e da duração do tratamento. A resposta clinica diferenciada de doentes infetados com diferentes subtipos do mesmo genótipo de $\mathrm{VHC}$, e no contexto de já ter sido descrito na literatura para os subtipos 1a e 1b, continua a colocar hipóteses de investigação sobre a importância do subtipo do vírus na progressão da doença crónica pelo $\mathrm{VHC} .{ }^{14}$

Disponibilizada a partir de 2007 e amplamente utilizada para genotipagem do VHC, a nova versão do ensaio comercial vulgarmente conhecido como LiPA, apresenta fraco desempenho na determinação ou descriminação dos subtipos virais, particularmente em infeções pelo genótipo 4. Em 2009, o laboratório nacional de referência no INSA implementou um ensaio molecular in-house visando obter uma melhoria na classificação do $\mathrm{VHC} .{ }^{15}$ Assim, foram objetivos do estudo, determinar o padrão molecular da infeção durante os últimos seis anos com base numa análise retrospetiva dos resultados de genotipagem do VHC obtidos entre 2009 e 2014; e para melhoria da caracterização molecular da infeção, mostrar o contributo de um ensaio in-house na determinação dos subtipos de VHC.

\section{MATERIAL E MÉTODOS}

\section{Amostras clinicas, 2009 - 2014}

Durante o período em análise foi realizada a genotipagem do VHC pelo ensaio comercial LiPA a 923 amostras clínicas colhidas a indivíduos com infeção ativa, das quais foram selecionadas 112 para subtipagem do VHC por um novo ensaio in-house implementado no laboratório. Em acordo com a proveniência das amostras, estas foram distribuídas por três grupos populacionais: 724 foram integradas no grupo de 'reclusos', 155 no grupo de indivíduos da 'população geral' (sem comportamentos de risco identificados) e 44 no grupo de 'UDI'. Em relação à distribuição das amostras por género, 842 foram colhidas a homens e 81 a mulheres. A idade média da população analisada variou anualmente entre 35,3 e 42,4 anos de idade (Tabela 1).

\section{Metodologia}

Foi realizada uma análise retrospetiva dos resultados obtidos da genotipagem do VHC pelo ensaio comercial VERSANT ${ }^{\mathrm{TM}}$ HCV Genotype 2.0 Assay-LiPA (Siemens

Tabela 1 - Caracterização da população de indivíduos cujas amostras clínicas foram estudadas para genotipagem do VHC, 2009-2014

\begin{tabular}{|c|c|c|c|c|c|c|c|}
\hline \multirow[b]{2}{*}{ Ano } & \multirow[b]{2}{*}{$\begin{array}{l}\text { Total } \\
\text { (n) }\end{array}$} & \multirow[b]{2}{*}{$\begin{array}{c}\text { Homens } \\
\% \text { (n) }\end{array}$} & \multirow[b]{2}{*}{$\begin{array}{l}\text { Mulheres } \\
\text { \% (n) }\end{array}$} & \multirow[b]{2}{*}{$\begin{array}{l}\text { Idade } \\
\text { média } \\
\text { (n) }\end{array}$} & \multicolumn{3}{|c|}{ Grupo Populacional } \\
\hline & & & & & $\begin{array}{c}\text { População } \\
\text { em geral } \\
\% \text { (n) }\end{array}$ & $\begin{array}{c}\text { Reclusos* }^{*} \\
\%(n)\end{array}$ & $\begin{array}{l}\text { UDI } \\
\%(n)\end{array}$ \\
\hline 2009 & 226 & $93,4 \%(211)$ & $6,6 \%(15)$ & $36,5(110)$ & $10,6 \%(24)$ & $88,9 \%(201)$ & $0,4 \%(1)$ \\
\hline 2010 & 214 & $92,5 \%(198)$ & $7,5 \%(16)$ & $35,3(71)$ & $16,4 \%(35)$ & $79,4 \%(170)$ & $4,2 \%(9)$ \\
\hline 2011 & 71 & $83,1 \%(59)$ & $16,9 \%(12)$ & $42,4(57)$ & $25,4 \%(18)$ & $38,0 \%(27)$ & $36,6 \%(26)$ \\
\hline 2012 & 138 & $92,8 \%(128)$ & $7,2 \%(10)$ & $39,6(116)$ & $16,7 \%(23)$ & $77,5 \%(107)$ & $5,8 \%(8)$ \\
\hline 2013 & 140 & $85,7 \%(120)$ & $14,3 \%(20)$ & $41,2(106)$ & $23,6 \%(33)$ & $76,4 \%(107)$ & 0 \\
\hline 2014 & 134 & $94,0 \%(126)$ & $6,0 \%(8)$ & $41,1(122)$ & $16,4 \%(22)$ & $83,6 \%(112)$ & 0 \\
\hline Total & 923 & $91,2 \%(842)$ & $8,8 \%(81)$ & $39,9(582)$ & $16,8 \%(155)$ & $78,4 \%(724)$ & $4,8 \%(44)$ \\
\hline
\end{tabular}

* Neste grupo populacional não podem ser excluídos eventuais comportamentos de risco para a infeção VHC, nomeadamente o uso de drogas injetáveis (UDI) 
Tabela 2 - Variação anual da proporção de genótipos do VHC identificados por LiPA, 2009-2014

\begin{tabular}{|c|c|c|c|c|c|}
\hline Ano & $\begin{array}{c}\text { Genótipo } 1 \\
\% \text { (n) }\end{array}$ & $\begin{array}{c}\text { Genótipo } 2 \\
\% \text { (n) }\end{array}$ & $\begin{array}{c}\text { Genótipo } 3^{*} \\
\%(n)\end{array}$ & $\begin{array}{c}\text { Genótipo } 4^{\S} \\
\%(n)\end{array}$ & $\begin{array}{c}\text { Inconclusivo } \\
\%(n)\end{array}$ \\
\hline 2009 & $52,3 \%(134)$ & $1,8 \%(4)$ & $27,4 \%(62)$ & $11,0 \%(25)$ & $0,4 \%(1)$ \\
\hline 2010 & $57,9 \%(124)$ & $2,3 \%(5)$ & $21,0 \%(45)$ & $15,9 \%(34)$ & $2,8 \%(6)$ \\
\hline 2011 & $57,7 \%(41)$ & 0 & $21,1 \%(15)$ & $15,5 \%(11)$ & $5,6 \%(4)$ \\
\hline 2012 & $51,4 \%(71)$ & 0 & $35,5 \%(49)$ & $12,3 \%(17)$ & $0,7 \%(1)$ \\
\hline 2013 & $50,7 \%(71)$ & $0,7 \%(1)$ & $33,6 \%(47)$ & $14,3 \%(20)$ & $0,7 \%(1)$ \\
\hline 2014 & $60,4 \%(81)$ & $2,2 \%(3)$ & $26,9 \%(36)$ & $8,6 \%(12)$ & $1,5 \%(2)$ \\
\hline Total & $56,6 \%(522)$ & $1,4 \%(13)$ & $27,5 \%(254)$ & $12,9 \%(119)$ & $1,6 \%(15)$ \\
\hline
\end{tabular}

* Todos os casos foram classificados de subtipo 3a; § Inclui casos não subtipados de genótipo 4 e casos de subtipo indiscriminado 4a/4c/4d; $\uparrow$ Inclui seis casos de potenciais infeções mistas por dois diferentes genótipos: genótipos 1 e 3 , genótipos 1 e 4 , e genótipos 3 e 4 .

Healthcare Diagnostics, NY, USA), e também, dos resultados obtidos na subtipagem por um ensaio molecular in-house baseado na amplificação e sequenciação das regiões genómicas Core/E1 e NS5B do VHC. As condições de reação deste ensaio encontram-se já descritas na literatura. $^{15}$

\section{RESULTADOS \\ Genotipagem do VHC}

Os resultados de genotipagem ao longo do período em análise revelaram uma maior frequência de infeções pelo genótipo 1 (56,6\%, variando entre $50,7 \%$ e $60,4 \%$ ), seguida do genótipo $3(27,5 \%$, variando entre $21,0 \%$ e $35,5 \%)$ e do genótipo 4 (12,9\%, variando entre $8,6 \%$ e $15,9 \%)$. O genótipo 2 foi o menos frequente $(1,4 \%$, variando entre $0 \%$ e $2,3 \%$ ) e não foram identificados casos de infeção pelos genótipos 5, 6 e 7 (Tabela 2). Verificou-se, ainda, que 1,6\% das amostras analisadas apresentaram um resultado in- conclusivo pelo método LiPA, incluindo seis casos que revelaram um perfil compatível com infeção mista por diferentes genótipos de VHC, nomeadamente casos de infeções por genótipos 1 e 3, genótipos 1 e 4, e genótipos 3 e 4 .

A infeção pelo genótipo 2 foi rara, e as infeções pelos genótipos 1 e 3 foram as mais prevalentes ao longo dos seis anos em análise e com uma frequência semelhante e independente dos vários grupos populacionais analisados (população em geral, reclusos e UDI) (Fig.1, Tabela 2). Por outro lado, para o mesmo período em análise, verificou-se uma frequência média de $12,9 \%$ de infeções pelo genótipo 4, apresentando-se crescente entre 2009 a 2013, respetivamente de $11 \%$ a $14,3 \%$ (Tabela 2 ).

\section{Subtipagem do VHC}

No presente estudo, observámos que do total dos casos classificados em genótipo 1, cerca de $80,8 \%(422 / 522)$ pertenciam ao subtipo 1a e $17,0 \%$ (89/522) pertenciam ao

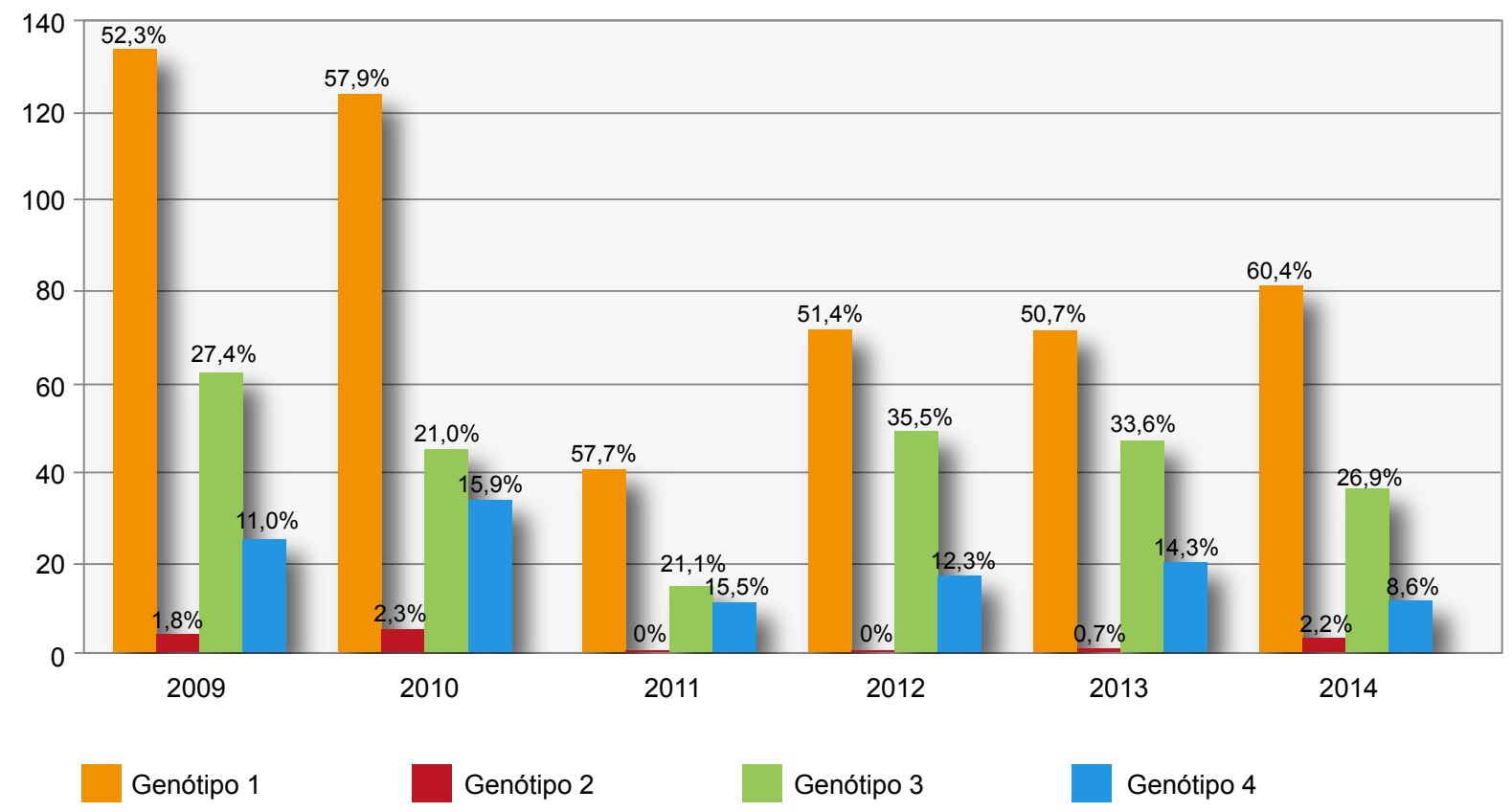

Figura 1 - Proporção anual de genótipos do VHC identificados pelo ensaio comercial LiPA, 2009-2014 
subtipo 1b. Em 2,1\% (11/522) dos casos não foi possível subtipar o vírus pelo ensaio comercial LiPA. Verificou-se ainda, que a diferença proporcional entre a frequência do subtipo 1a e a do subtipo $1 \mathrm{~b}$ foi constante em cada ano e ao longo do período em análise, sendo sempre cerca de quatro vezes superior no subtipo 1a (Fig. 2).

O subtipo $3 a$ foi o único subtipo de vírus identificado no grupo de infeções pelo genótipo 3 , correspondendo a $27,5 \%$ das amostras estudadas (Tabela 2 ).

Não foi possível subtipar o VHC em 156 (16,9\%) das 923 amostras clínicas submetidas ao ensaio comercial LiPA: em $114(73,1 \%)$ o subtipo não foi descriminado e em $42(26,9 \%)$ o subtipo não foi determinado.

As amostras não subtipadas que apresentavam volume de soro suficiente foram submetidas ao ensaio in-house ( $n=83$ ) para a amplificação e sequenciação das regiões genómicas Core/E1 e/ou NS5B do VHC, tendo sido todas subtipadas com sucesso. Assim, no grupo de amostras não subtipadas e classificadas como genótipo $4(n=55)$ em LiPA, verificou-se que o subtipo 4 a foi o mais frequente $(65,5 \%)$, seguindo-se o subtipo $4 d(32,7 \%)$, sendo também identificado um caso de subtipo 4c (Tabela 3 e Fig. 3). Adicionalmente, também foi classificada uma amostra em subtipo $4 \mathrm{~b}$ pelo ensaio in-house que apresentava resultado inconclusivo em LiPA (Tabela 3). De referir ainda, que o ensaio molecular implementado permitiu a deteção do recombinante intergenótipo RF1_2k/1b e de três variantes intragenótipo 2 (estimativa filogenética, dados não apresentados), ainda não descritas na base de dados internacional de sequências de VHC (Tabela 3 ).

\section{DISCUSSÃO}

Em Portugal, são raros os estudos de epidemiologia molecular do VHC realizados, sendo ainda pouco conhecida a prevalência dos genótipos e subtipos virais na população infetada do país. Assim, o presente estudo retros- petivo desenvolvido no laboratório de referência do INSA, integrando uma detalhada caracterização molecular do VHC, pode dar um importante contributo para aumentar o conhecimento sobre a diversidade de vírus em circulação no país, particularmente nos grupos populacionais de onde são provenientes as amostras analisadas, incluindo as alterações temporais no padrão molecular das infeções.

As infeções pelos genótipos 1, 2 e 3 do VHC têm sido descritas como sendo as mais prevalentes a nível mundial, nomeadamente nos continentes europeu e americano. ${ }^{16,17}$ Um estudo clínico realizado por investigadores portugueses há cerca de 15 anos atrás ${ }^{18}$ revelava já uma elevada prevalência de infeções pelo genótipo 1 , maioritariamente associada ao subtipo $1 \mathrm{~b}$, e uma frequência significativa de infeções pelo subtipo 3a. Descrevia-se uma frequência baixa de infeção pelo genótipo 2 e ausência de casos de infeção pelo genótipo 4. Mais recentemente, estudos retrospetivos de caracterização molecular do VHC desenvolvidos em grupos populacionais de UDI e de reclusos ${ }^{15,16}$ revelaram que em infeções pelo genótipo 1 e 4 , respetivamente, existia um predomínio do subtipo 1a e do subtipo 4a. Todos os estudos descreviam uma baixa frequência de infeção pelo genótipo 2. Os resultados obtidos no presente estudo, para além de confirmarem uma elevada prevalência da infeção pelos genótipos 1 (subtipo 1a) e 3 (subtipo $3 a)$, mostra também que a infeção pelo genótipo 2 continua a ser esporádica. Os resultados sugerem ainda, um possível aumento na prevalência de infeções pelo genótipo 4, o que foi observado entre 2009 a 2013.

Estudos epidemiológicos indicam que o subtipo $1 \mathrm{~b}$ é prevalente a nível mundial, encontrando-se amplamente distribuído na Europa e em alguns países de África e do sudoeste asiático, associado a indivíduos de idade avançada e que adquiriram a infeção por via transfusional no passado. ${ }^{6,16,17}$ No presente estudo, e apesar do viés da seleção da amostra, observámos que as infeções pelo subtipo $1 \mathrm{~b}$

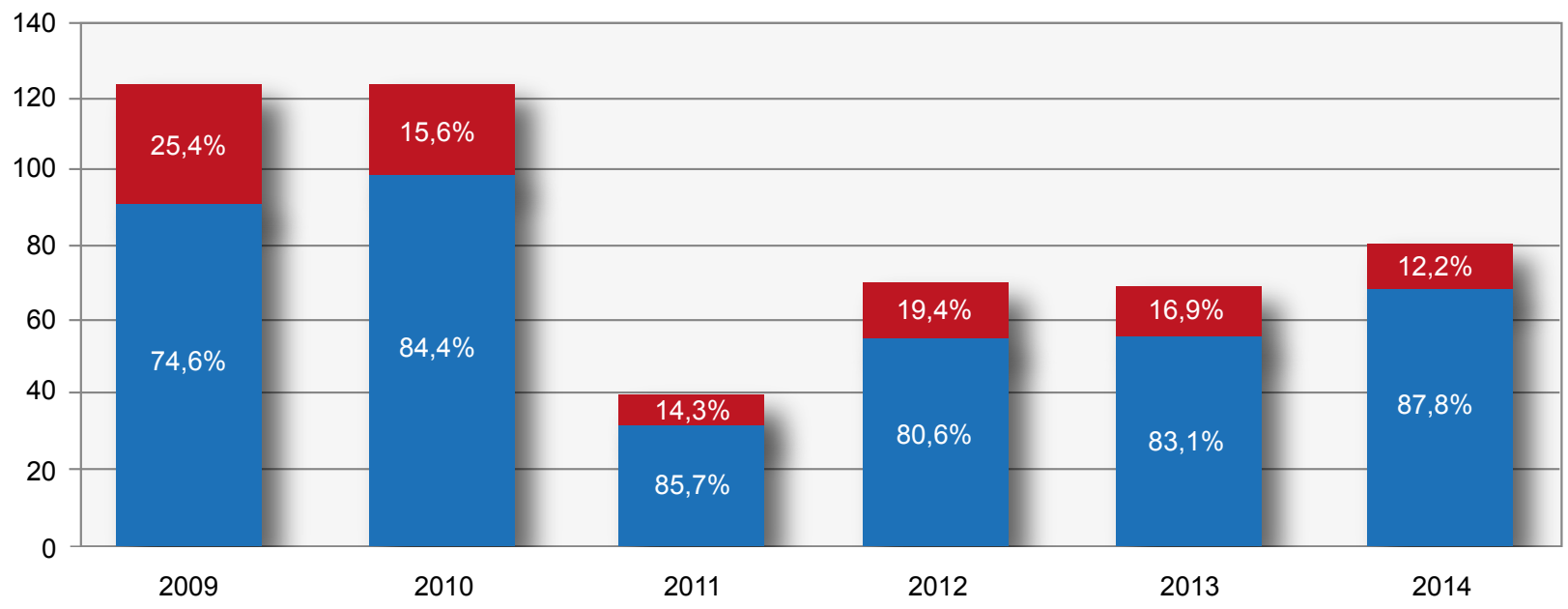


apresentam uma frequência cerca de quatro vezes menor comparativamente ao subtipo 1a, estando a infeção relacionada com indivíduos reclusos de uma faixa etária jovem.

O segundo subtipo mais frequente nas amostras estudadas foi o subtipo 3a que à semelhança do que acontece para o subtipo 1a, foi descrito ser comum nos UDI de vários países europeus. ${ }^{16,17,19}$ Porém, apesar da maioria dos indivíduos estudados ser reclusa, os eventuais comportamentos de risco associados ao consumo de drogas ilícitas não podem ser excluídos do grupo populacional.

A infeção pelo genótipo 4 é prevalente no Médio Oriente e em África, estando associada a $62 \%$ e $90 \%$ das infeções identificadas, respetivamente, na Arábia Saudita e no Egito. Estudos revelam que a infeção pelo genótipo 4 se manteve endémica por um longo período de tempo na África Central e Ocidental sendo suportada pela continuidade de práticas de circuncisão, escarificação, ou por via de transmissão sexual. A disseminação para outras regiões do continente africano, coincidiu com a campanha de vacinação massiva realizada entre os anos 1920 e $1940 .{ }^{13,20}$ A elevada diversidade genética do vírus observada na África Subsariana conduziu à hipótese de que o genótipo 4 teve origem na África Central e Ocidental, ocorrendo posteriormente, a sua disseminação no continente. ${ }^{13,17,20,21}$ Em contraste com a heterogenei-

Tabela 3 - Classificação do VHC pelo ensaio comercial LiPA e pelo novo ensaio in-house implementado no laboratório

\begin{tabular}{|c|c|c|c|c|c|c|c|c|c|c|c|c|}
\hline \multirow{2}{*}{$\begin{array}{l}\text { LiPA vs } 2.0 \\
\text { (5'UTR + core) }\end{array}$} & \multicolumn{11}{|c|}{ Sequenciação das regiões Core + E1 e/ou NS5B do VHC } & \multirow{2}{*}{$\begin{array}{c}\text { Total } \\
\mathbf{n}\end{array}$} \\
\hline & 1a & $1 b$ & $2 k / 1 b^{*}$ & $2^{\S}$ & $2 a$ & $2 b$ & $3 a$ & $4 a$ & $4 b$ & 4c & $4 d$ & \\
\hline 1 & 7 & 4 & & & & & & & & & & 11 \\
\hline $1 \mathrm{a}$ & 10 & & & & & & & & & & & 10 \\
\hline $1 \mathrm{~b}$ & & 12 & & & & & & & & & & 12 \\
\hline 2 & & & & 1 & 1 & 2 & & & & & & 4 \\
\hline $2 a / 2 c$ & & & 1 & 2 & 2 & & & & & & & 5 \\
\hline $2 b$ & & & & & & 1 & & & & & & 1 \\
\hline $3 a$ & & & & & & & 6 & & & & & 6 \\
\hline 4 & & & & & & & & 4 & & & 3 & 7 \\
\hline $4 a / 4 c / 4 d$ & & & & & & & & 32 & & 1 & 15 & 48 \\
\hline Inconclusivo & 1 & 2 & & & & & 2 & 2 & 1 & & & 8 \\
\hline Total (n) & 18 & 18 & 1 & 3 & 3 & 3 & 8 & 38 & 1 & 1 & 18 & 112 \\
\hline
\end{tabular}

*As sequências obtidas foram classificadas em RF1_2k/1b, recombinante descrito por Kalinina et al. 2002²3; § Outros estudos moleculares classificaram o vírus em recombinantes intragenótipo 2 .

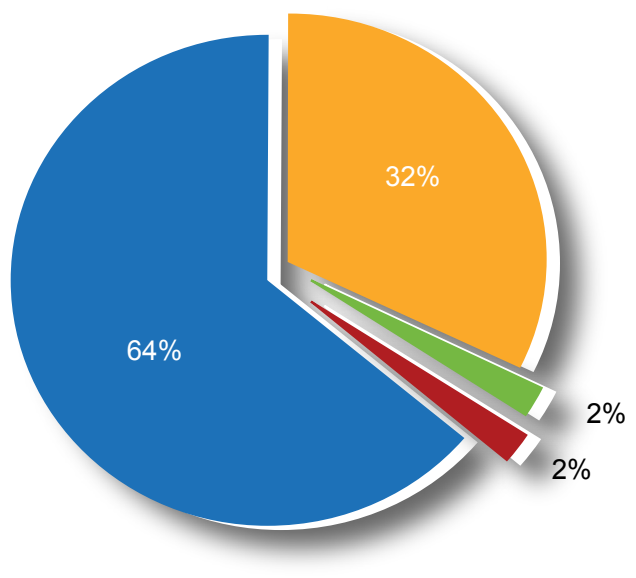

Subtipo $4 a$ Subtipo 4b

Figura 3 - Proporção de subtipos 4a, 4b, 4c e 4d do VHC identificada, 2009-2014 
dade das variantes do genótipo 4 em circulação na África Subsariana, o padrão molecular da infeção no Egito é homogéneo e com o predomínio do subtipo 4a, sendo referido que a transfusão sanguínea seria a forma frequente de transmissão do vírus na população até há poucos anos atrás. Por outro lado, na Arábia Saudita os subtipos predominantes são $4 \mathrm{c} / 4 \mathrm{~d}$ seguidos do $4 \mathrm{~h}$, $4 \mathrm{e}$ e $4 \mathrm{a}$, sugerindo existir potenciais diferenças na origem ou vias de transmissão do vírus neste país. Em países europeus, nomeadamente, em Espanha, França, Itália e Grécia, foi descrito o aumento da prevalência dos subtipos $4 \mathrm{~d}$ e 4 a associado ao movimento dos UDI e à entrada na Europa de imigrantes de países endémicos para a infeção. .0,21 $^{20}$ No presente estudo e ao longo do período em análise, foi encontrada uma proporção relativamente elevada de infeção pelo subtipo $4 a$, seguida do subtipo $4 d$, e apenas identificada através do ensaio in-house implementado. Adicionalmente, também foi detetada a infeção pelo subtipo $4 \mathrm{~b}$, já anteriormente descrita em Portugal, ${ }^{22}$ bem como do subtipo 4c. Estes resultados indicam existir uma elevada diversidade genética na infeção pelo genótipo 4 no nosso país.

O primeiro recombinante de VHC, a RF1_2k/1b, foi identificado em 2002 em S. Petersburgo, ${ }^{23}$ no entanto, estudos posteriores mostraram a sua disseminação em UDI de vários países europeus. ${ }^{24}$ No presente estudo, o ensaio in-house implementado permitiu a deteção de um caso de infeção pela RF1_2k/1b e de três casos de infeções por recombinantes intragenótipo 2 (dados não apresentados). De facto, embora na literatura seja referido que a frequência de recombinação do VHC é baixa, vários casos de infeção por recombinantes foram identificados em alguns estudos portugueses, ${ }^{15,16}$ o que fundamenta uma vigilância da epidemiologia molecular da infeção e da sua dinâmica, bem como o estudo do eventual impacto clinico destas variantes virais.

\section{CONCLUSÕES}

Apesar do viés de seleção da amostra estudada, da análise retrospetiva efetuada para estes últimos seis anos, verificou-se que a infeção pelo subtipo 1a foi a mais frequente, sendo esta quatro vezes superior à frequência da infeção pelo subtipo 1b. Por outro lado, a infeção pelo genótipo 2 mostrou ser esporádica, sendo identificados os subtipos $2 \mathrm{a}$ e $2 \mathrm{~b}$. A infeção pelo genótipo 3 foi exclusivamente classificada em subtipo 3a, e a infeção pelo genótipo 4 revelou ser relativamente frequente e caracterizada por elevada diversidade de vírus, sendo identificados os subtipos 4a, 4b, 4c e 4d. Observámos ainda, a presença de infeção com formas geneticamente recombinadas de VHC.

$\mathrm{O}$ padrão molecular da infeção do $\mathrm{VHC}$ obtido neste estudo é compatível com uma epidemia associada a comportamentos de risco no consumo de drogas ilícitas, e que tem sido frequentemente descrita em grupos populacionais de UDI no nosso país. O elevado desempenho revelado pelo ensaio in-house na correta classificação do vírus e identificação de formas recombinadas do VHC, possibilita a melhoria na classificação dos vírus em circulação na população residente em Portugal. Esta metodologia pode contribuir para aumentar o conhecimento do papel da diversidade genética na história natural e progressão para doença crónica, independentemente da nova era no tratamento da hepatite $\mathrm{C}$ que se avizinha.

\section{PROTECÇÃO DE PESSOAS E ANIMAIS}

Os autores declaram que os procedimentos seguidos estavam de acordo com os regulamentos estabelecidos pelos responsáveis da Comissão de Investigação Clínica e Ética e de acordo com a Declaração de Helsínquia da Associação Médica Mundial.

\section{CONFIDENCIALIDADE DOS DADOS}

Os autores declaram ter seguido os protocolos do seu centro de trabalho acerca da publicação dos dados de doentes.

\section{CONFLITO DE INTERESSES}

Os autores declaram não ter nenhum conflito de interesses relativamente ao presente artigo.

\section{FONTES DE FINANCIAMENTO}

Não existiram fontes externas de financiamento para a realização deste artigo.

\section{REFERÊNCIAS}

1. Lavanchy D. The global burden of hepatitis C. Liver Int. 2009;29:74-81

2. Jafari N, Farajzadegan Z, Ataei B. Surveillance system for hepatitis C infection: a practical approach. Int J Prev Med. 2012;3:S48-57.

3. Hepatitis C - global prevalence (uptade). Wkly Epidemiol Rec 2000;75:18-9

4. Lavanchy D. Evolving epidemiology of hepatitis C virus. Clin Microbiol Infect. 2011;17:107-15

5. Marinho R, Moura M, Giria J, Ferrinho P. Epidemiological aspects of hepatitis C in Portugal. J Gastroenterol Hepatol. 2001;16:1076-7.

6. Marinho RT, Lavanchy D. Viral hepatitis. Meeting News. 2011;19:1-24.

7. Vieira AM, Freire R, Mangualde J, Pinho C, Fernandes V, Alves AL, et al. Hepatite C - casuística da consulta de hepatologia de um hospital distrital. J Port Gastroenterol. 2007;14:134-40.

8. Calado RA, Rocha MR, Parreira R, Piedade J, Venenno T, Esteves A. Hepatitis $C$ virus subtypes circulating among intravenous drug users in Lisbon, Portugal. J Med Virol. 2011;83:608-15.

9. Smith DB, Bukh J, Kuiken C, Muerhoff AS, Rice CM, Stapleton JT, et

al. Expanded classification of hepatitis $C$ virus into 7 genotypes and 67 subtypes: update criteria and genotype assignment web resource. Hepatology. 2014;59:318-27.

10. Bukh J, Miller R, Purcell R. Biology and genetic heterogeneity of hepatitis C virus. Clin Exp Rheumatol. 1995;13:S3-7

11. Feld $\mathrm{J}$, Hoofnagle $\mathrm{J}$. Mechanism of action of interferon and ribavirin in treatment of hepatitis C. Nature. 2005;436:967-72.

12. EASL Clinical Practice Guidelines: Management of hepatitis $C$ virus infection. J Hepatol. 2014;60:392-420.

13. Antaki N, Craxi A, Kamal S, Moucari R, Van der Merwe S, Haffar S, et al. The neglected hepatitis $C$ virus genotypes 4,5 and 6 : an international consensus report. Liver Int. 2010;30:342-55.

14. Zein NN, Poterucha JJ, Gross JB Jr, Wiesner RH, Therneau TM, Gossard AA, et al. Increased risk of hepatocellularcarcinoma in patients infected with hepatitis C genotype1b. Am J Gastroenterol. 1996;91:25602

15. Avó AP, Água-Doce I, Andrade A, Pádua E. Hepatitis C virus subtyp- 
ing based on sequencing of the C / E1 and NS5B genomic regions in comparison to a commercially available line probe assay. J Med Virol. 2013;85:815-22.

16. Esteban J, Sauleda S, Quer J. The changing epidemiology of hepatitis C virus infection in Europe. J Hepatol. 2008;48:148-62.

17. Simmonds P. Genetic diversity and evolution of hepatitis C virus-15 years on. J Gen Virol. 2004;85:3173-88.

18. De Carvalho A, Martinho A, Leitão J, Cipriano MA, Coimbra H, Porto A. HGenotipos do VHC. Histopatologia hepática e perfil imunológico em quatro grupos de doentes. Acta Med Port. 2000;13:67-75.

19. Van Asten L, Verhaest I, Lamzira S, Hernandez-Aguado I, Zangerle R, Boufassa $F$, et al. Spread of hepatitis $C$ virus among European injection drug users infected with HIV: a phylogenetic analysis. J Infect Dis. 2004;189:292-302.

20. Kamal SM, Nasser IA. Hepatitis $C$ genotype 4: what we know and what we don't yet know. Hepatology. 2008;47:1371-83.
21. Bruijne J, Schinkel J, Prins M, Koekkoek SM, Aronson SJ, Van Ballegooijen MW, et al. Emergence of hepatitis $C$ virus genotype 4: phylogenetic analysis reveals three distinct epidemiological profiles. J Clin Microbiol. 2009;7:3832-8.

22. Koletzki D, Dumont S, Vermeiren H, Peixe P, Nina J, Camacho RJ, et al. Full genome sequence of three isolates of hepatitis $C$ virus subtype $4 \mathrm{~b}$ from Portugal. Arch Virol. 2009;154:127-32.

23. Kalinina $\mathrm{O}$, Norder H, Mukomolov S, Magnius LO. A natural intergenotypic recombinant of hepatitis $\mathrm{C}$ virus identified in St. Petersburg. J Virol. 2002;76:4034-43.

24. Ramière $C$, Tremeaux $P$, Caporossi A, Trabaud MA, Lebossé F, Bailly $F$, et al. Recent evidence of underestimated circulation of hepatitis $C$ virus intergenotypic recombinant strain $\mathrm{RF} 2 \mathrm{k} / 1 \mathrm{~b}$ in the Rhône-Alpes region, France, January to August 2014: implications for antiviral treatment. Euro Surveill. 2014;19:20944. 


\section{Conhecer a Diversidade do Vírus da Hepatite} C Para Além da Frequência dos Genótipos em Amostras Analisadas entre 2009 e 2014 no Laboratório de Referência do Instituto Nacional de Saúde Dr. Ricardo Jorge

Acta Med Port 2015:28:695-701

Publicado pela Acta Médica Portuguesa, a Revista Científica da Ordem dos Médicos

Av. Almirante Gago Coutinho, 151

1749-084 Lisboa, Portugal.

Tel: +351218428 215

E-mail: submissao@actamedicaportuguesa.com

www.actamedicaportuguesa.com

ISSN:0870-399X | e-ISSN: 1646-0758

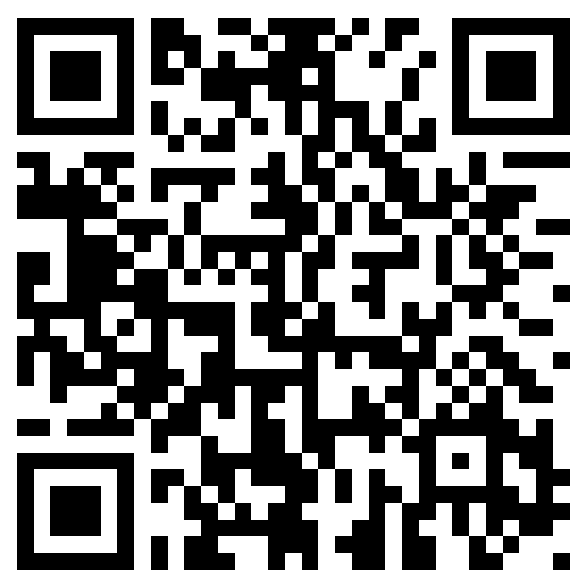

